\title{
Inorganic phosphate and the risk of cancer in the Swedish AMORIS study
}

\author{
Wahyu Wulaningsih ${ }^{1}$, Karl Michaelsson ${ }^{2}$, Hans Garmo ${ }^{1,3}$, Niklas Hammar ${ }^{4,5}$, Ingmar Jungner ${ }^{6}$, Göran Walldius ${ }^{4}$, \\ Lars Holmberg ${ }^{1,3}$ and Mieke Van Hemelrijck ${ }^{1 *}$
}

\begin{abstract}
Background: Both dietary and serum levels of inorganic phosphate (Pi) have been linked to development of cancer in experimental studies. This is the first population-based study investigating the relation between serum Pi and risk of cancer in humans.

Methods: From the Swedish Apolipoprotein Mortality Risk (AMORIS) study, we selected all participants (> 20 years old) with baseline measurements of serum Pi, calcium, alkaline phosphatase, glucose, and creatinine ( $n=397,292)$. Multivariable Cox proportional hazards regression analyses were used to assess serum Pi in relation to overall cancer risk. Similar analyses were performed for specific cancer sites.

Results: We found a higher overall cancer risk with increasing Pi levels in men ( HR: 1.02 (95\% Cl: 1.00-1.04) for every SD increase in Pi), and a negative association in women (HR: 0.97 (95\% Cl: 0.96-0.99) for every SD increase in Pi). Further analyses for specific cancer sites showed a positive link between Pi quartiles and the risk of cancer of the pancreas, lung, thyroid gland and bone in men, and cancer of the oesophagus, lung, and nonmelanoma skin cancer in women. Conversely, the risks for developing breast and endometrial cancer as well as other endocrine cancer in both men and women were lower in those with higher Pi levels.
\end{abstract}

Conclusions: Abnormal Pi levels are related to development of cancer. Furthermore, the inverse association between Pi levels and risk of breast, endometrial and other endocrine cancers may indicate the role of hormonal factors in the relation between Pi metabolism and cancer.

Keywords: Cancer, Inorganic phosphate, Prospective cohort study

\section{Background}

Dietary patterns are suggested to be an important environmental risk factor for cancer [1]. Inorganic phosphate $(\mathrm{Pi})$ is a dietary constituent well-known for its role in skeletal mineralization, and normal levels of $\mathrm{Pi}$ are essential to maintain normal cellular function [2]. Recent experimental studies in rodents indicated that Pi may act as an active regulator of growth rather than a merely compulsory element in cellular homeostasis. Elevated levels of serum $\mathrm{Pi}$ were found to modify gene expression as well as protein translation and affect the rate of cell proliferation in vitro $[3,4]$. Moreover, a high $\mathrm{Pi}$ diet has been reported to result

\footnotetext{
* Correspondence: mieke.vanhemelrijck@kcl.ac.uk

'King's College London, School of Medicine, Division of Cancer Studies, Cancer Epidemiology Unit, London, UK

Full list of author information is available at the end of the article
}

in a significantly increased development of lung and skin cancers, as well as perturbed normal brain growth in animal studies [5-7], which denoted the potential link between Pi and carcinogenesis in humans. However, to our knowledge there are no observational studies describing the association between $\mathrm{Pi}$ and cancer risk in humans.

Besides being naturally present in raw food including meats, fish, eggs, dairy products and vegetables, $\mathrm{Pi}$ is also found as an additive in processed food such as hamburgers and pizza, and as phosphoric acid in soda beverages [8]. Mostly, this Pi content is not listed as an ingredient per se, and it was reported that this 'hidden' $\mathrm{Pi}$ content of food with Pi-containing additives is nearly $70 \%$ higher than in food without additives [9]. In the human body $\mathrm{Pi}$ is known to be mainly regulated by a set of

\section{Biomed Central}


hormonal and metabolic factors which tightly control calcium homeostasis, i.e. vitamin $\mathrm{D}$ and parathyroid hormone $(\mathrm{PTH})$, and a recently identified $\mathrm{Pi}$ regulating hormone, fibroblast growth factor 23 (FGF-23). However, intestinal absorption of Pi is efficient and minimally regulated $[2,10]$, so that high $\mathrm{Pi}$ supplementation results in markedly elevated levels of serum $\mathrm{Pi}[11,12]$. Additionally, abnormal Pi levels are also a common feature of various metabolic diseases including diabetes and rickets $[13,14]$. Considering the emerging experimental evidence linking $\mathrm{Pi}$ and cancer, it is of interest to explore this relation in an observational population-based setting.

\section{Methods}

\section{Study population and data collection}

The Swedish Apolipoprotein Mortality Risk (AMORIS) database has been described in detail elsewhere [15-17]. Briefly, this database is based on the linkage of the Central Automation Laboratory (CALAB) database (1985-1996) to various Swedish national registries, including the National Cancer Register. The CALAB database includes data from 351,487 male and 338,101 female individuals having clinical laboratory testing as part of a general health check-up or outpatients referred for laboratory testing. No individuals were inpatients at the time their blood samples were taken. This study complied with the Declaration of Helsinki, and the ethics review board of the Karolinska Institutet approved the study (diary number: 2010/1047-31/1).

We selected all participants aged 20 or older with baseline measurements of serum $\mathrm{Pi}$, calcium $(\mathrm{mmol} / \mathrm{L})$, alkaline phosphatase $(\mathrm{mmol} / \mathrm{L})$, glucose $(\mathrm{mmol} / \mathrm{L})$ and creatinine $(\mu \mathrm{mol} / \mathrm{L})(\mathrm{n}=397,292)$. All participants were free from cancer at time of entry and none were diagnosed with cancer or died within three months after study entry. Follow-up time was defined as the time from measurement until date of cancer diagnosis, emigration, death, or study closing date $\left(31^{\text {st }}\right.$ of December 2002), whichever occurred first. The CALAB database also contained information on age, season at time of measurement, and fasting status. Diagnosis of cancer were obtained from the National Cancer Register and classified based on the International Classification of Diseases, seventh revision (ICD-7; codes for specific cancer sites are presented in tables). Socioeconomic status (SES) was taken from the consecutive Swedish censuses during 1970-1990 and is based on occupational groups and classifies gainfully employed subjects into manual workers and non-manual employees, below designated as blue-collar and white-collar workers [18]. History of hospitalization for diabetes (ICD-7: 260) and lung disease (ICD-7: 470-527; mostly include upper and lower respiratory tract infections and did not include asthma) was obtained from the National Patient Register.
Serum inorganic phosphate was measured via formation of the phosphomolybdic acid complex (coefficient of variation $\leq 4 \%$ ) [19]. To assess the effect of small changes in serum Pi levels, we calculated standardized values of Pi using its standard deviation (SD) as a unit. Calcium and alkaline phosphatase were measured by colorimetric method [20,21], while glucose was measured enzymatically with a glucose-oxidase/peroxidase method [22]. Serum creatinine was measured with the Jaffé method (kinetic) [23]. All laboratory examinations were performed using described methods above with automated and calibrated instruments in the same laboratory [24].

\section{Data analysis}

Multivariate Cox proportional hazards models were used to investigate quartiles and standardized values of serum $\mathrm{Pi}$ as a continuous variable in relation to overall incident cancer. All models were adjusted for age, gender and SES. We also took into account serum glucose, fasting status and history of diabetes based on hospital discharge diagnosis since diabetes is known to modify the risk of cancer and Pi metabolism is abnormal in diabetic persons [13,25]. The levels of $\mathrm{Pi}$ as well as other metabolic markers potentially related to cancer are also altered in metabolic bone disease [26-28], so that additional adjustment for alkaline phosphatase, a marker of bone turnover, was performed. Our database did not have information regarding phosphate regulators, i.e. vitamin D, FGF23 and parathyroid hormone (PTH) [2,29], but we used season at time of baseline measurement as a proxy for vitamin $\mathrm{D}$ [30]. Kidney function is also a potential confounder as renal reabsorption of $\mathrm{Pi}$ is a major component in maintaining physiological Pi levels, and kidney disease is a risk factor of cancer [31,32]. Thus, serum creatinine was used in the multivariable models. Further adjustment was done for history of lung disease as a proxy for smoking as the latter has been strongly linked to an increased risk of respiratory tract infection [33] To assess reverse causation [34], we performed a sensitivity analysis in which those with follow-up $<3$ years were excluded $(n=10,360)$. Finally, we conducted sex-stratified analyses of Pi and risk of specific cancer sites using quartiles and standardized values of Pi. All analyses were conducted with Statistical Analysis Systems (SAS) release 9.1.3 (SAS Institute, Cary, NC).

\section{Results}

A total of 31,482 persons developed cancer during mean follow-of 12.75 years. Most measurements were taken as part of health examinations done at company health check-ups, so that the majority of the study population (84\%) was gainfully employed (Table 1). The age of the participants, serum glucose, alkaline phosphatase and creatinine were higher in the population with cancer 
Table 1 Baseline characteristics of study population

\begin{tabular}{lcc}
\hline & \multicolumn{2}{c}{$\mathbf{N}(\%)$} \\
\cline { 2 - 3 } & $\begin{array}{c}\text { No cancer } \\
(\mathbf{N = 3 6 5 , 8 1 0 )}\end{array}$ & $\begin{array}{c}\text { Cancer } \\
(\mathbf{N}=\mathbf{3 1 , 4 8 2})\end{array}$ \\
\hline Age (years) - Mean (SD) & $44.00(14.00)$ & $55.71(11.93)$ \\
\hline Sex & & \\
\hline Male & $193769(52.97)$ & $16903(53.69)$ \\
\hline Semale & $172041(47.03)$ & $14579(46.31)$ \\
\hline White Collar & & \\
\hline Blue Collar & $132733(36.28)$ & $12064(38.32)$ \\
\hline Not gainfully employed & $174385(47.67)$ & $14009(44.50)$ \\
or Missing & $58692(16.04)$ & $5409(17.18)$ \\
\hline
\end{tabular}

\section{Fasting status}

\begin{tabular}{|c|c|c|}
\hline Fasting & $208923(57.11)$ & $19547(62.09)$ \\
\hline Non-fasting & $113613(31.06)$ & $8153(25.90)$ \\
\hline Missing & $43274(11.83)$ & $3782(12.01)$ \\
\hline Follow-up time (years) - Mean (SD) & $13.12(3.89)$ & $8.39(4.68)$ \\
\hline $\mathrm{Pi}^{1}$ (mmol/L) Mean (SD) & $1.06(0.17)$ & $1.04(0.16)$ \\
\hline Calcium (mmol/L) Mean (SD) & $2.39(0.10)$ & $2.39(0.10)$ \\
\hline $\begin{array}{l}\text { Alkaline phosphatase (mmol/) } \\
\text { Mean (SD) }\end{array}$ & $2.64(0.96)$ & $2.78(1.02)$ \\
\hline Glucose (mmol/L) - Mean (SD) & $4.97(1.29)$ & $5.19(1.48)$ \\
\hline Creatinine $(\mu \mathrm{mol} / \mathrm{L})$ - Mean $(S D)$ & $81.70(15.22)$ & $83.77(16.76)$ \\
\hline \multicolumn{3}{|l|}{ Season } \\
\hline Winter & $93580(25.58)$ & $8328(26.45)$ \\
\hline Spring & $99572(27.22)$ & $8747(27.78)$ \\
\hline Summer & $55799(15.25)$ & $4601(14.61)$ \\
\hline Fall & 116859 (31.95) & $9806(31.15)$ \\
\hline History of diabetes (ICD-7 260) & $1905(0.52)$ & $201(0.64)$ \\
\hline History of lung disease (ICD-7 470-527) & $23709(6.48)$ & $1791(5.69)$ \\
\hline
\end{tabular}

than those without cancer. Pi levels were slightly higher in the group without cancer, while no marked difference in calcium levels was noted between the two groups.

Multivariable Cox proportional hazards ratios for quartiles of Pi showed a lower risk of overall cancer for those in the $3^{\text {rd }}$ and $4^{\text {th }}$ quartiles of Pi for both men and women. This pattern of risk was also observed for women, but in men higher quartiles were associated with an increased risk of cancer. When we excluded persons with follow-up $<3$ years, the positive association between Pi quartiles and overall cancer risk for men weakened slightly (Table 2). When using standardized Pi instead of quartiles, there was a negative association with risk of overall cancer (HR per SD: 0.97 (95\% CI: 0.960.99), P-value $<0.0001)$. Excluding the first three years of follow-up did not change the results.

When investigating the relation between quartiles of Pi and risk of different types of cancer in men, we found
Table 2 Hazard ratios and $95 \%$ confidence intervals for the risk of overall cancer for quartiles and standardized values of serum Pi levels

\begin{tabular}{|c|c|c|}
\hline & $\begin{array}{l}\text { Overall cancer } \\
\text { Hazard ratio } \\
(95 \% \mathrm{Cl})\end{array}$ & $\begin{array}{c}\text { Overall cancer }^{1} \\
\text { Hazard ratio } \\
(95 \% \mathrm{Cl})\end{array}$ \\
\hline \multicolumn{3}{|l|}{ Men and women combined } \\
\hline Standardized Pi (SD = 0.17) & $0.97(0.96-0.99)$ & $0.98(0.96-0.99)$ \\
\hline \multicolumn{3}{|l|}{ Quartiles of Pi $(\mathrm{mmol} / \mathrm{L})$} \\
\hline$<0.95$ & 1.00 (Ref) & 1.00 (Ref) \\
\hline $0.95-1.05$ & $0.98(0.96-1.02)$ & $1.00(0.97-1.03)$ \\
\hline $1.05-1.16$ & $0.94(0.91-0.97)$ & $0.95(0.91-0.98)$ \\
\hline$\geq 1.16$ & $0.94(0.91-0.97)$ & $0.95(0.92-0.98)$ \\
\hline P-value for trend & $<0.0001$ & $<0.0001$ \\
\hline \multicolumn{3}{|l|}{$\mathrm{Men}^{2}$} \\
\hline Standardized $\mathbf{P i}(S D=0.17)$ & $1.02(1.00-1.04)$ & $1.02(1.00-1.04)$ \\
\hline \multicolumn{3}{|l|}{ Quartiles of $\mathrm{Pi}(\mathrm{mmol} / \mathrm{L})$} \\
\hline$<0.92$ & 1.00 (Ref) & 1.00 (Ref) \\
\hline $0.92-1.03$ & $1.06(1.02-1.10)$ & $1.05(1.01-1.09)$ \\
\hline $1.03-1.14$ & $1.04(1.00-1.08)$ & $1.03(0.98-1.08)$ \\
\hline$\geq 1.14$ & $1.07(1.03-1.12)$ & $1.06(1.01-1.12)$ \\
\hline P-value for trend & 0.01 & 0.05 \\
\hline \multicolumn{3}{|l|}{ Women $^{2}$} \\
\hline Standardized Pi (SD = 0.16) & $0.97(0.96-0.99)$ & $0.97(0.95-0.99)$ \\
\hline \multicolumn{3}{|l|}{ Quartiles of $\mathbf{P i}(\mathrm{mmol} / \mathrm{L})$} \\
\hline$<0.99$ & 1.00 (Ref) & 1.00 (Ref) \\
\hline $0.99-1.09$ & $0.95(0.91-0.99)$ & $0.98(0.93-1.04)$ \\
\hline $1.09-1.19$ & $0.93(0.89-0.97)$ & $0.93(0.89-0.99)$ \\
\hline$\geq 1.19$ & $0.91(0.87-0.96)$ & $0.93(0.88-0.98)$ \\
\hline P-value for trend & $<0.0001$ & 0.001 \\
\hline
\end{tabular}

All models were adjusted for age, sex, SES, fasting status, calcium, alkaline phosphatase, glucose, creatinine, season, history of diabetes and lung diseases. 'A sensitivity analysis excluding the first three years of follow-up $(n=386,683)$. ${ }^{2}$ Not adjusted for sex.

a statistically significant increase in the risk of pancreatic, lung, thyroid, bone and other cancer in those with higher Pi quartiles (Table 3). Additionally, a higher risk of developing cancer of the liver and gallbladder was found in men in the highest Pi quartile (HR: 1.38 (95\% CI: 1.00-1.91) for the fourth quartile of Pi compared to the first). Using standardized $\mathrm{Pi}$, a positive association was also observed between increasing standardized $\mathrm{Pi}$ and the risk of non-Hodgkin's lymphoma in men, but no linear association was observed using quartiles of $\mathrm{Pi}$. However, there was an inverse association between $\mathrm{Pi}$ levels and risk of endocrine cancer other than the thyroid gland, prostate, and testis (e.g. HR 0.87 (95\% CI: 0.76-1.00) per SD increase of Pi, P-value < 0.0001), although the trend over the quartiles was not linear. There was also a borderline inverse association between standardized Pi and risk of colorectal cancer, but this was not confirmed by Pi quartiles. Excluding other endocrine 
Table 3 Hazard ratios and $95 \%$ confidence intervals for the risk of site-specific cancer for quartiles of serum Pi in men

\begin{tabular}{|c|c|c|c|c|c|c|c|}
\hline \multirow[t]{2}{*}{ Cancer site (ICD-7) } & \multirow[t]{2}{*}{$n$ cases } & \multicolumn{4}{|c|}{ Quartiles of $\mathrm{Pi}(\mathrm{mmol} / \mathrm{L}), \mathrm{HR}(95 \% \mathrm{Cl})$} & \multirow{2}{*}{$\begin{array}{l}\text { P-value } \\
\text { for trend }\end{array}$} & \multirow{2}{*}{$\begin{array}{l}\text { Standardized } \\
\mathrm{Pi}, \mathrm{HR}(95 \% \mathrm{Cl})\end{array}$} \\
\hline & & $<0.92$ & $0.92-1.03$ & $1.03-1.14$ & $\geq 1.14$ & & \\
\hline Lip, oral cavity, pharynx (140-149) & 135 & 1.00 (Ref) & $1.12(0.71-1.77)$ & $1.15(0.71-1.86)$ & $1.28(0.77-2.12)$ & 0.31 & $1.10(0.93-1.30)$ \\
\hline Oesophagus (150) & 196 & 1.00 (Ref) & $1.23(0.84-1.80)$ & $1.26(0.84-1.89)$ & $1.43(0.94-2.18)$ & 0.17 & $1.12(0.98-1.28)$ \\
\hline Stomach (151) & 400 & 1.00 (Ref) & $1.10(0.87-1.41)$ & $0.80(0.60-1.07)$ & $1.07(0.80-1.44)$ & 0.49 & $0.98(0.88-1.09)$ \\
\hline Colorectal $(153,154)$ & 1929 & 1.00 (Ref) & $1.06(0.94-1.18)$ & $0.95(0.84-1.08)$ & $0.91(0.79-1.05)$ & 0.07 & $0.95(0.91-1.00)$ \\
\hline Liver, gallbladder (155) & 319 & 1.00 (Ref) & $1.15(0.86-1.54)$ & $1.07(0.78-1.47)$ & $1.38(1.00-1.91)$ & 0.14 & $1.09(0.98-1.22)$ \\
\hline Pancreas (157) & 427 & 1.00 (Ref) & $1.32(1.03-1.71)$ & $1.27(0.97-1.68)$ & $1.41(1.05-1.88)$ & 0.02 & $1.11(1.02-1.22)$ \\
\hline Larynx (161) & 143 & 1.00 (Ref) & $1.13(0.72-1.77)$ & $1.33(0.84-2.10)$ & $1.28(0.78-2.10)$ & 0.24 & $1.11(0.95-1.29)$ \\
\hline Lung (162) & 1396 & 1.00 (Ref) & $1.24(1.07-1.42)$ & $1.22(1.05-1.42)$ & $1.35(1.15-1.58)$ & 0.002 & $1.10(1.04-1.15)$ \\
\hline Prostate (177) & 5075 & 1.00 (Ref) & $1.01(0.94-1.08)$ & $1.02(0.94-1.10)$ & $0.98(0.90-1.07)$ & 0.72 & $0.98(0.95-1.01)$ \\
\hline Testis (178) & 159 & 1.00 (Ref) & $0.98(0.60-1.58)$ & $0.97(0.60-1.57)$ & $1.11(0.70-1.75)$ & 0.62 & $1.02(0.88-1.19)$ \\
\hline Kidney (180) & 525 & 1.00 (Ref) & $1.05(0.84-1.32)$ & $1.14(0.90-1.44)$ & $0.87(0.66-1.15)$ & 0.49 & $1.03(0.94-1.13)$ \\
\hline Bladder (181) & 1181 & 1.00 (Ref) & $0.99(0.85-1.15)$ & $1.04(0.89-1.21)$ & $1.02(0.86-1.21)$ & 0.76 & $1.02(0.96-1.08)$ \\
\hline Melanoma of skin (190) & 765 & 1.00 (Ref) & $1.02(0.85-1.24)$ & $1.08(0.89-1.32)$ & $1.01(0.89-1.25)$ & 0.66 & $1.01(0.94-1.09)$ \\
\hline Nonmelanoma of skin (191) & 772 & 1.00 (Ref) & $0.95(0.80-1.14)$ & $0.90(0.74-1.10)$ & $1.13(0.91-1.39)$ & 0.46 & $0.98(0.91-1.06)$ \\
\hline Brain/central nervous system (193) & 527 & 1.00 (Ref) & $1.03(0.82-1.31)$ & $1.08(0.84-1.37)$ & $1.06(0.82-1.37)$ & 0.74 & $1.01(0.92-1.10)$ \\
\hline Thyroid gland (194) & 69 & 1.00 (Ref) & $0.94(0.45-1.98)$ & $1.76(0.90-3.43)$ & $1.69(0.85-3.38)$ & 0.04 & $1.15(0.93-1.41)$ \\
\hline Other endocrine organ (195) & 215 & 1.00 (Ref) & $0.46(0.31-0.66)$ & $0.44(0.29-0.65)$ & $0.67(0.47-0.96)$ & 0.03 & $0.87(0.76-1.00)$ \\
\hline Bone (196) & 1690 & 1.00 (Ref) & $1.15(1.02-1.31)$ & $1.15(1.01-1.32)$ & $1.25(1.08-1.10)$ & 0.002 & $1.06(1.01-1.11)$ \\
\hline Soft tissues (197) & 126 & 1.00 (Ref) & $1.48(0.93-2.37)$ & $1.13(0.67-1.92)$ & $1.42(0.83-2.42)$ & 0.32 & $1.11(0.95-1.30)$ \\
\hline Non-Hodgkin's lymphoma $(200,202)$ & 613 & 1.00 (Ref) & $1.24(1.00-1.52)$ & $1.06(0.84-1.33)$ & $1.22(0.96-1.55)$ & 0.25 & $1.08(1.00-1.17)$ \\
\hline Hodgkin's lymphoma (201) & 62 & 1.00 (Ref) & $0.98(0.82-1.18)$ & $1.01(0.99-1.02)$ & $1.45(0.95-2.22)$ & 0.51 & $0.92(0.71-1.20)$ \\
\hline Multiple myeloma (203) & 259 & 1.00 (Ref) & $1.31(0.96-1.77)$ & $0.84(0.57-1.21)$ & $1.20(0.83-1.74)$ & 0.82 & $1.02(0.90-1.16)$ \\
\hline Leukemia (204-207) & 398 & 1.00 (Ref) & $0.88(0.68-1.13)$ & $0.79(0.59-1.04)$ & $0.85(0.63-1.14)$ & 0.12 & $0.98(0.89-1.09)$ \\
\hline Other cancer $^{1}$ & 865 & 1.00 (Ref) & $1.15(0.96-1.38)$ & $1.23(1.02-1.49)$ & $1.38(1.13-1.68)$ & 0.003 & $1.10(1.03-1.18)$ \\
\hline
\end{tabular}

All models were adjusted for age, SES, fasting status, calcium, alkaline phosphatase, glucose, creatinine, season, history of diabetes and lung diseases.

'Other cancer than the separately presented sites.

ICD-7, International Classification of Diseases, seventh revision; ref, referent group. 
cancer resulted in a stronger association between $\mathrm{Pi}$ and overall cancer in men (e.g. HR: 1.10 (95\% CI: 1.03-1.18) per SD increase in $\mathrm{Pi}, \mathrm{P}$-value 0.003, results not shown in tables).

In women, higher Pi quartiles were related with an increased risk of oesophageal, lung, and nonmelanoma skin cancer (Table 4). The test for trend also showed a borderline positive association with risk of laryngeal cancer, but the limited number of cases resulted in low statistical power. Increased risks of stomach and bone cancer were also observed for women in higher quartiles of Pi compared to the first. In contrast, an inverse association was observed between Pi quartiles and risk of breast, endometrial and other endocrine cancers. Furthermore, there was an increased risk of colorectal cancer risk with every SD increase in $\mathrm{Pi}$, although this was not confirmed with Pi quartiles. When cancer of the breast, endometrium, and other endocrine organs were excluded from the analysis, the inverse association between $\mathrm{Pi}$ and overall cancer risk in women disappeared (e.g. HR: 1.06 (95\% CI: 0.98-1.15) for every SD increase in $\mathrm{Pi}, \mathrm{P}$-value 0.13 , results not shown in tables).

\section{Discussion}

This is the first study evaluating the association between $\mathrm{Pi}$ and risk of cancer in a population-based observational setting. We found a positive association between serum $\mathrm{Pi}$ and risk of overall cancer in men, but an inverse association for women using data from a large prospective Swedish cohort study. Higher Pi quartiles in men was related to pancreatic, lung, thyroid, bone and other cancers. In women, a positive trend was observed between Pi quartiles and risk of oesophageal, lung, and nonmelanoma skin cancer, while a negative association was seen in breast, endometrial, and other endocrine cancer.

The role of $\mathrm{Pi}$ in development of cancer has recently been suggested. Elevated levels of serum Pi were found to enhance gene expression as well as protein translation regulating cell proliferation in vitro [3,4]. Furthermore, a high phosphate diet has been reported to promote colonic cell hyperplasia and hyperproliferation in mice, indicating a role of $\mathrm{Pi}$ in carcinogenesis [35]. Elevated $\mathrm{Pi}$ has been suggested to promote development of cancer via amplifying Akt signaling activities and enhancing capdependent translation, eventually resulting in increased cell proliferation $[6,36]$. On the other hand, also mice treated with low dietary phosphate have been shown to develop increased tumourigenesis and enhanced activities of similar signaling pathways [37]. All these pre-clinical findings suggest that both high and low Pi may influence carcinogenesis.

The present study demonstrated that lower Pi was related to an increased risk of overall cancer in women, while higher Pi levels were linked to increased overall cancer risk in men. These associations remained clear after excluding first three years of follow-up, thus no reverse causation was indicated. Reverse causation between Pi and cancer is plausible since low Pi levels may be caused by increased Pi excretion. The latter is often reported in cancer patients and is suggested to occur through renal proximal tubular dysfunction due to administration of cytotoxic drugs or cancer progression [38]. This was unlikely to be the case in the current study.

In the current study, higher Pi levels were associated with an increased risk of male pancreas, lung, thyroid and bone cancer and female oesophagus, lung, and nomelanoma skin cancer. The consistent positive association between Pi levels and lung cancer corroborated prior biological findings linking high dietary Pi to a significantly increased tumor formation in mouse models of lung cancer [36]. Additionally, elevated serum Pi levels have also been reported to enhance the growth and proliferation of nontumourigenic human bronchial epithelial (NHBE) cells, and this process was linked to increased activation of PI3K/Akt as well as Raf/ MEK/ERK pathways which play an important role in carcinogenesis [4]. Nevertheless, when higher Pi doses were administered in similar experiments, a steep decrease in cell growth was observed, indicating the existence of a $\mathrm{Pi}$ threshold beyond normal range over which cytotoxicity occurs. Further investigation is necessary to define the acceptable range of Pi levels to maintain physiologic control of cell growth and function.

The observed relation between $\mathrm{Pi}$ and nonmelanoma skin cancer in women is also in line with previous experimental findings. In a study by Camalier and colleagues, female mouse models of skin tumorigenesis treated with high dietary Pi showed a 50\% increase of tumor formation upon 7, 12-dimethylbenz[a] anthracene/12-O-tetradecanoly phorbol-13-acetate (DMBA/TPA) treatment compared to those treated with low Pi diet [5]. It was suggested that Pi affects the formation of skin tumours partly through increased activation of $\mathrm{N}$-ras and its downstream targets [5]. For cancer of the brain/central nervous system, we observed no clear association with Pi levels, despite the reported effects of $\mathrm{Pi}$ on brain growth in animal studies. Jin et al. suggested that high dietary Pi reduces brain cell proliferation through suppression of cyclin D1 and PCNA, two marker proteins related to cell cycle [12]. Nevertheless, the same authors also reported increased apoptosis and related disruptions of cell cycle in normal brain cells of mice treated with low dietary Pi [7]. Both low and high levels of Pi are thus likely to impede normal proliferation of brain cells and may also play a role in carcinogenesis. However there is lack of observational studies linking Pi and brain cancer. For colorectal cancer, results in women corroborated the positive link with $\mathrm{Pi}$ as shown in experimental findings in mice, but opposing results were found in men [35]. 
Table 4 Hazard ratios and $95 \%$ confidence intervals for the risk of site-specific cancer for quartiles of serum Pi in women

\begin{tabular}{|c|c|c|c|c|c|c|c|}
\hline \multirow[t]{2}{*}{ Cancer site (ICD-7) } & \multirow[t]{2}{*}{$n$ cases } & \multicolumn{4}{|c|}{ Quartiles of $\mathrm{Pi}(\mathrm{mmol} / \mathrm{L}), \mathrm{HR}(95 \% \mathrm{Cl})$} & \multirow{2}{*}{$\begin{array}{l}\text { P-value } \\
\text { for trend }\end{array}$} & \multirow{2}{*}{$\begin{array}{c}\text { Standardized } \\
\text { Pi, HR }(95 \% \mathrm{Cl})\end{array}$} \\
\hline & & $<0.99$ & $0.99-1.09$ & $1.09-1.19$ & $\geq 1.19$ & & \\
\hline Lip, oral cavity, pharynx (140-149) & 66 & 1.00 (Ref) & $0.62(0.30-1.29)$ & $0.93(0.48-1.81)$ & $1.05(0.55-2.00)$ & 0.67 & $1.04(0.80-1.35)$ \\
\hline Oesophagus (150) & 75 & 1.00 (Ref) & $0.57(0.25-1.30)$ & $1.56(0.81-2.99)$ & $1.95(1.04-3.67)$ & 0.004 & $1.34(1.10-1.65)$ \\
\hline Stomach (151) & 251 & 1.00 (Ref) & $1.71(1.18-2.47)$ & $1.48(1.01-2.18)$ & $1.52(1.03-2.25)$ & 0.10 & $1.13(0.98-1.29)$ \\
\hline Colorectal $(153,154)$ & 1410 & 1.00 (Ref) & $1.06(0.91-1.23)$ & $1.04(0.89-1.21)$ & $1.11(0.96-1.30)$ & 0.22 & $1.06(1.00-1.12)$ \\
\hline Liver, gallbladder (155) & 260 & 1.00 (Ref) & $1.08(0.75-1.55)$ & $1.38(0.97-1.95)$ & $1.26(0.88-1.81)$ & 0.11 & $1.09(0.95-1.25)$ \\
\hline Pancreas (157) & 335 & 1.00 (Ref) & $1.08(0.80-1.46)$ & $0.93(0.67-1.28)$ & $1.24(0.92-1.68)$ & 0.28 & $1.04(0.93-1.18)$ \\
\hline Larynx (161) & 16 & 1.00 (Ref) & $2.86(0.30-27.58)$ & $7.31(0.90-59.67)$ & $5.72(0.66-49.37)$ & 0.05 & $1.36(0.85-2.17)$ \\
\hline Lung (162) & 887 & 1.00 (Ref) & $1.21(0.98-1.48)$ & $1.51(1.24-1.84)$ & $1.66(1.37-2.02)$ & $<0.0001$ & $1.20(1.12-1.29)$ \\
\hline Breast (170) & 4925 & 1.00 (Ref) & $0.94(0.87-1.01)$ & $0.89(0.82-0.96)$ & $0.81(0.75-0.88)$ & $<0.0001$ & $0.93(0.90-0.96)$ \\
\hline Cervix uteri (171) & 318 & 1.00 (Ref) & $1.12(0.82-1.53)$ & $1.09(0.80-1.51)$ & $1.12(0.82-1.54)$ & 0.52 & $1.03(0.91-1.16)$ \\
\hline Endometrium (172) & 900 & 1.00 (Ref) & $0.83(0.70-0.99)$ & $0.72(0.60-0.87)$ & $0.72(0.60-0.87)$ & 0.0002 & $0.84(0.78-0.91)$ \\
\hline Ovary (175) & 637 & 1.00 (Ref) & $1.00(0.81-1.24)$ & $0.97(0.78-1.20)$ & $0.90(0.72-1.13)$ & 0.31 & $0.98(0.90-1.07)$ \\
\hline Other parts of uterus $(174,176)$ & 67 & 1.00 (Ref) & $0.81(0.39-1.71)$ & $1.37(0.71-2.67)$ & $1.15(0.58-2.29)$ & 0.39 & $1.07(0.83-1.38)$ \\
\hline Kidney (180) & 262 & 1.00 (Ref) & $1.19(0.85-1.68)$ & $1.24(0.88-1.75)$ & $1.04(0.72-1.49)$ & 0.81 & $1.02(0.89-1.16)$ \\
\hline Bladder (181) & 325 & 1.00 (Ref) & $1.05(0.77-1.43)$ & $1.11(0.82-1.52)$ & $1.02(0.74-1.40)$ & 0.79 & $1.02(0.91-1.16)$ \\
\hline Melanoma of skin (190) & 532 & 1.00 (Ref) & $1.02(0.80-1.29)$ & $1.09(0.86-1.39)$ & $0.99(0.77-1.27)$ & 0.93 & $1.05(0.95-1.15)$ \\
\hline Nonmelanoma of skin (191) & 442 & 1.00 (Ref) & $1.47(1.12-1.94)$ & $1.33(1.00-1.77)$ & $1.53(1.16-2.04)$ & 0.01 & $1.12(1.01-1.24)$ \\
\hline Brain/central nervous system (193) & 456 & 1.00 (Ref) & $0.90(0.70-1.17)$ & $1.00(0.78-1.30)$ & $0.95(0.73-1.24)$ & 0.88 & $1.00(0.90-1.11)$ \\
\hline Thyroid gland (194) & 121 & 1.00 (Ref) & $0.77(0.45-1.30)$ & $1.14(0.70-1.85)$ & $0.99(0.60-1.63)$ & 0.65 & $1.06(0.88-1.27)$ \\
\hline Other endocrine organ (195) & 407 & 1.00 (Ref) & $0.33(0.25-0.43)$ & $0.15(0.11-0.43)$ & $0.19(0.14-0.26)$ & $<0.0001$ & $0.45(0.41-0.51)$ \\
\hline Bone (196) & 1080 & 1.00 (Ref) & $1.21(1.02-1.44)$ & $1.20(1.01-1.43)$ & $1.19(1.00-1.42)$ & 0.06 & $1.08(1.02-1.16)$ \\
\hline Soft tissues (197) & 93 & 1.00 (Ref) & $0.84(0.48-1.47)$ & $0.79(0.44-1.41)$ & $1.02(0.58-1.78)$ & 0.96 & $1.02(0.82-1.29)$ \\
\hline Non-Hodgkin's lymphoma $(200,202)$ & 419 & 1.00 (Ref) & $0.96(0.74-1.24)$ & $0.95(0.72-1.24)$ & $0.88(0.67-1.16)$ & 0.38 & $1.00(0.90-1.11)$ \\
\hline Hodgkin's lymphoma (201) & 39 & 1.00 (Ref) & $1.23(0.62-2.43)$ & $1.38(0.70-2.75)$ & $0.63(0.27-1.48)$ & 0.94 & $1.18(0.86-1.62)$ \\
\hline Multiple myeloma (203) & 140 & 1.00 (Ref) & $1.31(0.82-2.10)$ & $1.26(0.78-2.04)$ & $1.14(0.69-1.88)$ & 0.70 & $1.02(0.84-1.22)$ \\
\hline Leukemia (204-207) & 265 & 1.00 (Ref) & $0.74(0.51-1.06)$ & $0.94(0.67-1.32)$ & $1.26(0.91-1.74)$ & 0.07 & $1.09(0.95-1.24)$ \\
\hline Other cancer $^{1}$ & 720 & 1.00 (Ref) & $1.14(0.92-1.40)$ & $1.05(0.84-1.30)$ & $1.20(0.97-1.49)$ & 0.17 & $1.08(0.99-1.17)$ \\
\hline
\end{tabular}

All models were adjusted for age, SES, fasting status, calcium, alkaline phosphatase, glucose, creatinine, season, history of diabetes and lung diseases.

'Other cancer than the separately presented sites.

ICD-7, International Classification of Diseases, seventh revision; ref, referent group. 
We found a clear inverse association between Pi levels with risks of female breast and endometrial cancers as well as "other endocrine cancers", which drove the inverse relation with overall cancer risk in women. Breast and endometrial cancers are well-known to be affected by hormonal factors, especially estrogen $[39,40]$. Increased levels of estrogen are known to negatively regulate circulating $\mathrm{Pi}$, both directly and via modulation of PTH levels [41]. Therefore, it is possible that the inverse association between Pi levels and gynecological cancer risk in women reflects the underlying estrogen levels. Correspondingly, it is suggested that hormonal and metabolic factors regulating Pi, i.e. vitamin D, FGF-23 and PTH, are related to cancer incidence [42-44], and thus their abnormal levels may be responsible for the association between $\mathrm{Pi}$ and cancer risks. Finally, the klotho gene encoding the obligate coreceptor for FGF-23 is also a putative tumour suppressor gene [45], further implying the link between Pi regulation and carcinogenesis.

The major strength of this study is the large number of subjects with baseline measurements of serum $\mathrm{Pi}$, all measured in the same laboratory. The use of national registers provided detailed follow-up information on diagnosis of cancer, time of death, and emigration for all subjects. The AMORIS population was mainly selected based on the availability of blood samples from health check-ups in non-hospitalized individuals. However, this healthy cohort effect would not affect the internal validity of the current study and is likely to be minor since it has been shown that the AMORIS cohort is similar to the general working population of Stockholm County in terms of SES and ethnicity [46]. A limitation of this study is that there was no available data on dietary Pi intake or Pi regulators such as FGF23, PTH, and vitamin $\mathrm{D}$ [29]. There was no information on other possible confounders such as smoking status and alcohol consumption. History of lung disease was used as a proxy for smoking, however some confounding effect of smoking may remain. For the current study we did not have repeated measurements of phosphate to assess its fluctuations over time. Nonetheless, as alteration in phosphate levels is likely to occur in specific conditions, i.e. kidney disease, ricketts and diabetes, we adjusted the models for these diseases using serum creatinine, alkaline phosphatase, glucose and history of diabetes in order to more accurately reflect phosphate levels. Furthermore, a single measurement of phosphate has been used in many published studies to measure the relation between phosphate metabolism and other diseases $[47,48]$

\section{Conclusion}

Our findings provide novel epidemiological evidence revealing a decreased cancer risk in women with high Pi and increased risk in men with high Pi. However, women with high Pi displayed a higher risk for developing some specific cancers including oesophageal, lung, and nonmelanoma skin cancer. The persistent negative link between $\mathrm{Pi}$ levels and the risk of breast, endometrial and other endocrine cancers which drove the inverse relation between Pi and overall cancer risk in women may imply that Pi rather serves as a proxy for underlying hormonal or metabolic factors instigating carcinogenesis. Further studies in this field should take into account these hormonal and metabolic factors involved in Pi metabolism and also the role of dietary $\mathrm{Pi}$, while also addressing the impacts of other cancer-related effect modifiers beyond the coverage of the current study.

\section{Competing interest}

None declared. Niklas Hammar is employed by the AstraZeneca Sverige, Södertalje, Sweden and the views of the present study are his own and not necessarily any official views of the AstraZeneca Sverige.

\section{Authors' contributions}

WW designed the study, analyzed the data, interpreted analysis results, and wrote the paper. KM interpreted analysis results and edited the manuscript. HG NH IJ GW LH contributed to the analysis tools and database used in this study and edited the manuscript. MVH conceived and designed the study, interpreted analysis results, and edited the manuscript. All authors read and approved the final manuscript.

\section{Acknowledgements}

This research was also supported by the Experimental Cancer Medicine Centre at King's College London and also by the National Institute for Health Research (NIHR) Biomedical Research Centre based at Guy's and St Thomas' NHS Foundation Trust and King's College London. The views expressed are those of the author(s) and not necessarily those of the NHS, the NIHR or the Department of Health.

\section{Author details}

${ }^{1}$ King's College London, School of Medicine, Division of Cancer Studies, Cancer Epidemiology Unit, London, UK. ²Department of Surgical Sciences, Uppsala University, Uppsala, Sweden. ${ }^{3}$ Regional Cancer Centre, Uppsala University Hospital, Uppsala, Sweden. ${ }^{4}$ Department of Epidemiology, Insitute of Environmental Medicine, Karolinska Institutet, Stockholm, Sweden.

${ }^{5}$ AstraZeneca Sverige, Södertalje, Sweden. ${ }^{6}$ Department of Medicine, Clinical Epidemiological Unit, Karolinska Institutet and CALAB Research, Stockholm, Sweden.

Received: 7 January 2013 Accepted: 21 May 2013

Published: 24 May 2013

\section{References}

1. Randi G, Edefonti V, Ferraroni M, La Vecchia C, Decarli A: Dietary patterns and the risk of colorectal cancer and adenomas. Nutr Rev 2010, 68(7):389-408.

2. Takeda E, Yamamoto H, Nashiki K, Sato T, Arai H, Taketani Y: Inorganic phosphate homeostasis and the role of dietary phosphorus. J cellular and molecular med 2004, 8(2):191-200.

3. Conrads KA, Yi M, Simpson KA, Lucas DA, Camalier CE, Yu LR, Veenstra TD, Stephens RM, Conrads TP, Beck GR Jr: A combined proteome and microarray investigation of inorganic phosphate-induced pre-osteoblast cells. Molecular \& cellular proteomics : MCP 2005, 4(9):1284-1296.

4. Chang SH, Yu KN, Lee YS, An GH, Beck GR Jr, Colburn NH, Lee KH, Cho MH: Elevated inorganic phosphate stimulates Akt-ERK1/2-Mnk1 signaling in human lung cells. American J Respiratory Cell and Molecular Biology 2006, 35(5):528-539.

5. Camalier CE, Young MR, Bobe G, Perella CM, Colburn NH, Beck GR Jr: Elevated phosphate activates $\mathrm{N}$-ras and promotes cell transformation and skin tumorigenesis. Cancer Prev Res (Phila) 2010, 3(3):359-370.

6. Jin H, Chang SH, Xu CX, Shin JY, Chung YS, Park SJ, Lee YS, An GH, Lee KH, Cho $\mathrm{MH}$ : High dietary inorganic phosphate affects lung through altering protein 
translation, cell cycle, and angiogenesis in developing mice. Toxicological sciences : an official journal of the Society of Toxicology 2007, 100(1):215-223.

7. Jin H, Hwang SK, Kwon JT, Lee YS, An GH, Lee KH, Prats AC, Morello D, Beck GR Jr, Cho MH: Low dietary inorganic phosphate affects the brain by controlling apoptosis, cell cycle and protein translation. The J Nutritional Biochemistry 2008, 19(1):16-25.

8. Shutto Y, Shimada M, Kitajima M, Yamabe H, Razzaque MS: Lack of awareness among future medical professionals about the risk of consuming hidden phosphate-containing processed food and drinks. PLoS One 2011, 6(12):e29105.

9. Benini O, D'Alessandro C, Gianfaldoni D, Cupisti A: Extra-phosphate load from food additives in commonly eaten foods: a real and insidious danger for renal patients. J Ren Nutr 2011, 21(4):303-308.

10. Bansal VK: Serum Inorganic Phosphorus. In Clinical Methods: The History, Physical, and Laboratory Examinations. 3rd edition. Edited by Walker HK, Hall WD, Hurst JW. Boston; 1990.

11. Tan HL, Liew QY, Loo S, Hawkins R: Severe hyperphosphataemia and associated electrolyte and metabolic derangement following the administration of sodium phosphate for bowel preparation. Anaesthesia 2002, 57(5):478-483.

12. Jin H, Hwang SK, Yu K, Anderson HK, Lee YS, Lee KH, Prats AC, Morello D, Beck GR Jr, Cho MH: A high inorganic phosphate diet perturbs brain growth, alters Akt-ERK signaling, and results in changes in cap-dependent translation. Toxicol Sci 2006, 90(1):221-229.

13. Ditzel J, Lervang HH: Disturbance of inorganic phosphate metabolism in diabetes mellitus: its impact on the development of diabetic late complications. Curr Diabetes Rev 2010, 6(5):323-333.

14. Tiosano D, Hochberg Z: Hypophosphatemia: the common denominator of all rickets. J Bone and Mineral Metabolism 2009, 27(4):392-401.

15. Holme I, Aastveit AH, Hammar N, Jungner I, Walldius G: Uric acid and risk of myocardial infarction, stroke and congestive heart failure in 417,734 men and women in the Apolipoprotein MOrtality RISk study (AMORIS). J internal medicine 2009, 266(6):558-570.

16. Holme I, Aastveit AH, Hammar N, Jungner I, Walldius G: Relationships between lipoprotein components and risk of ischaemic and haemorrhagic stroke in the Apolipoprotein MOrtality RISk study (AMORIS). J internal medicine 2009, 265(2):275-287.

17. Jungner I, Sniderman AD, Furberg C, Aastveit AH, Holme I, Walldius G: Does lowdensity lipoprotein size add to atherogenic particle number in predicting the risk of fatal myocardial infarction? Am J Cardio/ 2006, 97(7):943-946.

18. Statistics Sweden. http://www.scb.se/.

19. Gamst O, Try K: Determination of serum-phosphate without deproteinization by ultraviolet spectrophotometry of the phosphomolybdic acid complex. Scand J Clin Lab Invest 1980, 40(5):483-486.

20. Alonso GL, Tumilasci OR, Nikonov JM: Improvement of a direct colorimetric method for calcium determination. Clin Chim Acta 1970, 27(3):549-551.

21. Pawar GB, Todai NK, Jaffar MB: A useful modification to the colorimetric assay of inorganic phosphorus and alkaline phosphatase in serum. Clin Chem 1978, 24(10):1847-1848

22. Purcell GV, Behenna DB, Walsh PR: Evaluation of the BMC glucose oxidase/peroxidase-4-aminophenazone-phenol procedure for glucose as adapted to the Technicon SMAC. Clin Chem 1979, 25(10):1844-1846.

23. Shoucri RM, Pouliot M: Some observations on the kinetics of the Jaffe reaction for creatinine. Clin Chem 1977, 23(9):1527-1530.

24. Jungner I, Marcovina SM, Walldius G, Holme I, Kolar W, Steiner E: Apolipoprotein B and A-I values in 147576 Swedish males and females, standardized according to the World Health Organization-International Federation of Clinical Chemistry First International Reference Materials. Clin Chem 1998, 44(8 Pt 1):1641-1649.

25. Ogunleye AA, Ogston SA, Morris AD, Evans JM: A cohort study of the risk of cancer associated with type 2 diabetes. Br J Cancer 2009, 101(7):1199-1201.

26. Williams CD, Whitley BM, Hoyo C, Grant DJ, Schwartz GG, Presti JC Jr, Iraggi JD, Newman KA, Gerber L, Taylor LA, et al: Dietary calcium and risk for prostate cancer: a case-control study among US veterans. Prev Chronic Dis 2012, 9:E39.

27. Shoback D: Update in osteoporosis and metabolic bone disorders. J Clin Endocrinol Metab 2007, 92(3):747-753.

28. Rollison DE, Cole AL, Tung KH, Slattery ML, Baumgartner KB, Byers T, Wolff RK: Giuliano. Vitamin D intake, vitamin D receptor polymorphisms, and breast cancer risk among women living in the southwestern U.S. Breast cancer research and treatment: AR; 2011.

29. Bergwitz C, Juppner $\mathrm{H}$ : Regulation of phosphate homeostasis by PTH, vitamin D, and FGF23. Annu Rev Med 2010, 61:91-104.
30. Michaelsson K, Baron JA, Snellman G, Gedeborg R, Byberg L, Sundstrom J, Berglund L, Arnlov J, Hellman P, Blomhoff R, et al: Plasma vitamin D and mortality in older men: a community-based prospective cohort study. Am J Clin Nutr 2010, 92(4):841-848.

31. Murer H, Biber J: Phosphate transport in the kidney. J Nephrol 2010, 23 (Suppl 16):S145-151.

32. Maisonneuve P, Agodoa L, Gellert R, Stewart JH, Buccianti G, Lowenfels AB, Wolfe RA, Jones E, Disney AP, Briggs D, et al: Cancer in patients on dialysis for end-stage renal disease: an international collaborative study. Lancet 1999, 354(9173):93-99.

33. Gally F, Chu HW, Bowler RP: Cigarette Smoke Decreases Airway Epithelial FABP5 Expression and Promotes Pseudomonas aeruginosa Infection. PLoS One 2013, 8(1):e51784.

34. Carpenter TO: Oncogenic osteomalacia-a complex dance of factors. N Eng J Med 2003, 348(17):1705-1708.

35. Newmark HL, Lipkin M, Maheshwari N: Colonic hyperplasia and hyperproliferation induced by a nutritional stress diet with four components of Western-style diet. J National Cancer Institute 1990, 82(6):491-496.

36. Jin H, Xu CX, Lim HT, Park SJ, Shin JY, Chung YS, Park SC, Chang SH, Youn $\mathrm{HJ}$, Lee $\mathrm{KH}$, et al: High dietary inorganic phosphate increases lung tumorigenesis and alters Akt signaling. Am J Respir Crit Care Med 2009, 179(1):59-68.

37. Xu CX, Jin H, Lim HT, Ha YC, Chae CH, An GH, Lee KH, Cho MH: Low dietary inorganic phosphate stimulates lung tumorigenesis through altering protein translation and cell cycle in K-ras(LA1) mice. Nutr Cancer 2010, 62(4):525-532

38. Miltiadous $G$, Christidis D, Kalogirou M, Elisaf M: Causes and mechanisms of acid-base and electrolyte abnormalities in cancer patients. Eur J Intern Med 2008, 19(1):1-7.

39. Beral V, Bull D, Reeves G: Endometrial cancer and hormone-replacement therapy in the Million Women Study. Lancet 2005, 365(9470):1543-1551.

40. Rossouw JE, Anderson GL, Prentice RL, LaCroix AZ, Kooperberg C, Stefanick ML, Jackson RD, Beresford SA, Howard BV, Johnson KC, et al: Risks and benefits of estrogen plus progestin in healthy postmenopausal women: principal results From the Women's Health Initiative randomized controlled trial. JAMA 2002, 288(3):321-333.

41. Uemura H, Irahara M, Yoneda N, Yasui T, Genjida K, Miyamoto Kl, Aono T, Takeda E: Close correlation between estrogen treatment and renal phosphate reabsorption capacity. J Clin Endocrinol Metab 2000, 85(3):1215-1219.

42. Cawthon PM, Parimi N, Barrett-Connor E, Laughlin GA, Ensrud KE, Hoffman AR, Shikany JM, Cauley JA, Lane NE, Bauer DC, et al: Serum 25-hydroxyvitamin $\mathrm{D}$, parathyroid hormone, and mortality in older men. J Clin Endocrinol Metab 2010, 95(10):4625-4634.

43. Jacobs E, Martinez ME, Buckmeier J, Lance P, May M, Jurutka P: Circulating fibroblast growth factor-23 is associated with increased risk for metachronous colorectal adenoma. J Carcinog 2011, 10:3.

44. Mulholland HG, Murray LJ, Anderson LA, Cantwell MM: Vitamin D, calcium and dairy intake, and risk of oesophageal adenocarcinoma and its precursor conditions. Br J Nutr 2011, 106(5):732-741.

45. Laitman Y, Kuchenbaecker KB, Rantala J, Hogervorst F, Peock S, Godwin AK, Arason A, Kirchhoff T, Offit K, Isaacs C, et al: The KL-VS sequence variant of Klotho and cancer risk in BRCA1 and BRCA2 mutation carriers. Breast Cancer Res Treat 2012, 132(3):1119-1126.

46. Van Hemelrijck M: Thesis for doctoral degree (PhD). Metabolic Syndrome and Prostate Cancer: Biomarkers and Treatment Side-effects. London: King's College London; 2010.

47. Dhingra R, Sullivan LM, Fox CS, Wang TJ, D'Agostino RB Sr, Gaziano JM, Vasan RS: Relations of serum phosphorus and calcium levels to the incidence of cardiovascular disease in the community. Arch Intern Med 2007, 167(9):879-885.

48. Larsson TE, Olauson $H$, Hagstrom E, Ingelsson E, Arnlov J, Lind L, Sundstrom $\mathrm{J}$ : Conjoint effects of serum calcium and phosphate on risk of total, cardiovascular, and noncardiovascular mortality in the community. Arterioscler Thromb Vasc Biol 2010, 30(2):333-339.

doi:10.1186/1471-2407-13-257

Cite this article as: Wulaningsih et al:: Inorganic phosphate and the risk of cancer in the Swedish AMORIS study. BMC Cancer 2013 13:257. 